\title{
Inner-city residents, ethnic minorities and primary health care
}

\author{
M. R. D. JOHNSON \\ M.A., Ph.D.
}

M. CROSS

B.Sc, M.A.

\author{
S. A. CARDEW \\ B.Sc.
}

Research Unit on Ethnic Relations (SSRC), St Peter's College, University of Aston, Birmingham B8 $3 T E \vec{\circ}$

\begin{abstract}
Summary
Ethnic minorities form a substantial proportion of the urban population. A household survey in the West Midlands assessed usage of primary and preventative health care services. Asian households made somewhat higher use of general practitioner (GP) facilities which can be related to demographic and socioeconomic status. Fewer differences were found than expected, and uptake of preventative services was good. Afro-Caribbean patterns were similar to those of whites.
\end{abstract}

KEY WORDS: health care provision, primary care, ethnic minorities.

\section{Introduction}

The presence of ethnic minorities in larger cities is not especially new, but until recently references to the 'immigrant problem' appeared to assume that it was a passing phase. Ethnic minorities now form about $4 \%$ of the population (and as much as $14 \%$ in Greater London, or nearly $11 \%$ in the Metropolitan West Midlands), and are a permanent part of the population, which culturally and socially will form a distinctive group of users of the health service. In particular, they form a large proportion of 'inner city' residents-as high as $71 \%$ in the Soho ward of Birmingham. Very often, even where there is some recognition of a minority presence, they are seen as a 'problem'. Indeed, in a recent Royal College of General Practitioners paper (Bolden, 1981), in all the areas surveyed, the presence of ethnic minorities was seen as placing a strain on general practitioners (GPs). In only one city was this seen as counterbalanced by the presence of doctors of Asian origin. There is a need for a detailed assessment of the objective situation. In particular, data from the West Midlands suggest that observations from London cannot always be of general relevance.

\section{Methods}

A large-scale household survey in inner areasiof the West Midlands conurbation (specifically in Sुelected wards of Birmingham, Coventry and Wolperhampton containing substantial proportions of ethic minority populations) was carried out in $1981^{\supset}$ to establish ethnic variations in service use and receipt, including data on primary health service provision. Households were identified using standard strati random sampling techniques and a simple randomized screening procedure. Response rates in excessof $80 \%$ were achieved and the population confirmeesas representative by reference to 1981 Censusoodata (Office of Population Census and Surveys, Fuller details are given in Johnson and Cross (in press). Information was obtained from the heafjof household or spouse by a trained interviewer, find relevant data from 2161 interviews is presented. Information has been extracted in particularöto examine whether ethnic minority clients make exeessive or unjustified demands upon the health service. In order to compare like with like, however, Bur survey dealt only with households containing peō le under the age of 60 as, while a third or more of inner city white residents are over this age, elderly ethinic minority residents are rare. Their problems hajve been addressed by a recent specific survey (Blagemore, 1982, 1983). Data here are presented categorized by 'ethnic group' based upon respondent solfassessment but confirmed by interviewer observation.

\section{Results}

Contrary to expectations, $99 \%$ of all groups (whike, Asian and Afro-Caribbean) were registered with an NHS general practitioner, and only about $10 \%$ were not registered with one practising in their immed area of residence (Table 1). Asians were most likely to be locally registered $(P<0.001)$, and two-thifds 
were registered with a GP of Asian origin, a further $10 \%$ being registered with practices containing an Asian doctor (Table 2). One in four of the whites in our survey was also registered either with an Asian doctor or a 'mixed' practice, as were more than one in 3 Afro-Caribbeans. Of the 171 practices identified, 59 were Asian and 21 'mixed'. It was notable that where more 'mixed' practices were to be found, white respondents suspicion of 'foreign doctors' was least!

It is sometimes stated that ethnic minorities represent a 'burden' on the health services by making excessive demands. Certainly, the survey demonstrated that Asian households were more likely to have visited their GP in the last year, and to have visited more frequently $(P<0.001)$ (Table 1$)$. AfroCaribbeans were not significantly more likely to have needed a doctor, although those who had done so tended to have been more frequently, often for longstanding conditions or for repeat prescriptions. However, whites were much more likely to have bypassed the GP by visiting hospital 'out-patient' or 'emer gency' clinics while these services were used by ethnic minorities only following referral by their GP. Further, while Asians were most likely to have had a domiciliary visit, Afro-Caribbeans were least likely to have called the GP out, and white responses were close to those of Asians. Given the larger numbers of children in Asian households, one might reasonably expect them to be more likely to need a domiciliary visit.

Equally, it should be added that (at least according to our respondents) few of their visits to the GP were for 'vague or poorly described symptoms' (as we classified their responses). This suggested to us that the visits were genuinely based on need and stemmed more from physical ailments than psychological problems. Indeed, most of the psychological-based consultations were reported by white respondents. While we accept that there may be cultural differences in 'presenting symptoms', particularly as regards mental health, it was expected that physical presentations of mental conditions would be reported

TABLE 1. GP registration and consultation rates in previous year

\begin{tabular}{lrrr}
\hline & White & Asian & Afro-Caribbean \\
\hline$n$ & 915 & 867 & 365 \\
Locally registered (\%) & 88 & 96 & 89 \\
Registered elsewhere (\%) & 11 & 4 & 10 \\
Not registered (\%) & 1 & & $(2)^{*}$ \\
$\quad \chi^{2}=49 \cdot 0$ with 4 d.f., $P<0.001$ & & & \\
$n$ & 916 & 876 & 365 \\
No visits in year (\%) & 32 & 13 & 23 \\
One/two in year (\%) & 35 & 21 & 31 \\
$3-5$ in year (\%) & 15 & 25 & 23 \\
6 or more in year (\%) & 18 & 24 & 3 \\
Not known (\%) & - & 17 & \\
& & & \\
$\chi^{2}=305 \cdot 8$ with 8 d.f., $P<0.001$ & & &
\end{tabular}

TABLE 2. Ethnicity of general practice with which registered

\begin{tabular}{lrrr}
\hline & \multicolumn{3}{c}{ Ethnicity of respondent } \\
\cline { 2 - 4 } & White & Asian & Afro-Caribbean \\
\hline Doctors & & & \\
$n$ & 850 & 820 & 340 \\
All white (\%) & 75 & 25 & 61 \\
Mixed (\%) & 15 & 10 & 9 \\
All Asian (\%) & 9 & 66 & \\
& & & \\
$\chi^{2}=587.7$ with 4 d.f., $P<0.001$ & & & 62 \\
Number of practices & & & 8 \\
White & 83 & 54 & 26 \\
Mixed & 20 & 11 & \\
Asian & 31 & 49 & \\
$\chi^{2}=22.5$ with 4 d.f., $P<0.001$ & & & \\
\hline
\end{tabular}


in such a form as to be considered 'vague or poorly described'.

While Asian parents appeared to be marginally less likely to have attended Child Health Clinics, the differences were very slight and certainly gave no cause for alarm. Indeed, their take-up of immunization services was considerably better than that of white parents in the survey, particularly few having had only some of the recommended vaccinations $(P<0.001)$. When considering immunization against rubella, Afro-Caribbeans reported nearly $90 \%$ takeup compared to only about $70 \%$ of whites and Asians $(P<0.01)$ (Table 3).

Finally, we consider the proposition that Asians do not believe in 'western medicine' or rely heavily on Unani or Ayurvedic practitioners (Eagle, 1980). While this may be the case in Bradford or London, in the West Midlands we found peculiarly little use of these non-western methods. They were as likely as whites (but not more so) to have consulted a private doctor-while a surprising proportion of Afro-Caribbeans had paid to go privately for a second opinion or for 'better treatment'. Virtually none of our white or Asian respondents had been to a herbalist or 'nonwestern' healer, although a small number of whites had patronized osteopaths. In answer to an opinion question, the majority of Asians felt that scient fic medicine was preferable to traditional remedies, under a quarter believing the latter had value for many conditions. White respondents, on the ot $\overline{\text { ger }}$ hand, were quite likely to believe this, as were AffoCaribbeans $(P<0.001)$ (Table 4).

\section{Conclusions}

While there are differences between ethnic grouxps in British society, there do not represent any major threat to the National Health Service, or an excessfye demand upon its resources by minority communitios. Where there is higher usage, it would appear to ${ }^{3} e$ linked to needs which can be closely related to sưch sociological inequalities as housing, employment affd income. Nor is it the case that the ethnic minoritites are opting out of the National Health, thereby creating a reservoir of illness or a subsystem wheh could threaten community health schemes. We thesefore hope that future research will cease to regard ethnic minorities as problem groups, but will instead seek to examine their needs as individuals and their

TABLE 3. For those with children under 5: attendance at Child Health Clinic and immunization uptake $(\%)$

\begin{tabular}{lrrc}
\hline & White & Asian & Afro-Caribbean \\
\hline$n$ & 172 & 357 & 59 \\
Taken to clinic (\%) & 93 & 90 & 88 \\
\multicolumn{1}{c}{$\chi^{2}=1.58$ with 2 d.f. } & & & \\
$n$ & 174 & 361 & 59 \\
Had all vaccinations* (\%) & 43 & 66 & 53 \\
Had some but not all (\%) & 45 & 22 & 34 \\
Not immunized (\%) & 11 & 9 & 10 \\
$\quad P<0.001$ & & &
\end{tabular}

For those whose oldest secondary school child is a girl: rubella immunization

\begin{tabular}{|c|c|c|c|}
\hline $\begin{array}{l}\text { Immunized } \\
\text { Not done } \\
\text { Don't know } \\
\quad 0.01>P>0.001 \\
\quad \chi^{2}=15 \cdot 2 \text { with } 4 \text { d.f. }\end{array}$ & $\begin{array}{r}90 \\
72 \\
21 \\
7\end{array}$ & $\begin{array}{r}152 \\
69 \\
14 \\
16\end{array}$ & $\begin{array}{r}67 \\
88 \\
7 \\
4\end{array}$ \\
\hline \multicolumn{4}{|c|}{$\begin{array}{l}\text { *Diptheria, tetanus, whooping cough and polio. 'Don't knows' excluded from } \chi^{2} \text { calculations. } \\
\text { TABLE 4. Belief that there are many conditions for which traditional remedies are better than } \\
\text { 'conventional' medicine }\end{array}$} \\
\hline & White & Asian & Afro-Caribbean \\
\hline $\begin{array}{l}n \\
\text { Agree } \\
\text { Don't know } \\
\text { Disagree } \\
\quad \chi^{2}=69.8 \text { with } 4 \text { d.f., } P<0.001 \text {. }\end{array}$ & $\begin{array}{r}776 \\
33 \\
22 \\
45\end{array}$ & $\begin{array}{r}734 \\
24 \\
24 \\
52\end{array}$ & $\begin{array}{r}286 \\
51 \\
14 \\
34\end{array}$ \\
\hline
\end{tabular}


problems in the context of other aspects of racial discrimination and disadvantage.

\section{Acknowledgment}

The research described in this paper was funded by the SSRC.

\section{References}

Bolden, K. (1981) Inner Cities, Royal College of General Practitioners, Occasional Paper 19.
BLAKEMORE, K. (1982) Health and illness among the elderly of minority ethnic groups. Health Trends, 14, 69.

BLAKEMORE, K. (1983) Ethnicity, self-reported illness and use of medical services by the elderly. Postgraduate Medical Journal, 59, 668.

EAGLE, R. (1980) Your friendly neighbourhood Hakim. World Medicine, 15, 21.

Johnson, M. \& Cross, M. (1983) Surveying service users: the methodology of the urban institutions project. RUER Working Paper, University of Aston (in press).

OfFice OF Population Census AND SURveYs (1982) 1981 CensusCounty Monitor $43 S$ (Birmingham). 